\title{
Associations between Flavonoid Intakes and Gut Microbiota in a Group of Adults with Cystic Fibrosis
}

\author{
$\mathrm{Li} \mathrm{Li}^{1}$ and Shawn Somerset ${ }^{2, *}$ \\ 1 School of Medicine, Menzies Health Institute Queensland, Griffith University, 68 University Drive, \\ Meadowbrook, QLD 4131, Australia; li.li14@griffithuni.edu.au \\ 2 Faculty of Health, University of Canberra, University Drive, Bruce, ACT 2617, Australia \\ * Correspondence: shawn.somerset@canberra.edu.au; Tel.: +61-6201-5380
}

Received: 29 July 2018; Accepted: 3 September 2018; Published: 7 September 2018

\begin{abstract}
Dietary flavonoid intakes can influence gut microbiota (GM), which in turn can affect immune function and host metabolism, both vital considerations in cystic fibrosis (CF) management. In CF, GM may be altered and link to CF respiratory events. This study explored the relationship between flavonoid intakes and GM in free-living adults with CF. Associations between the overall GM variations (unweighted and weighted UniFrac distances between pyrosequencing results of bacterial 16-ss rDNA from frozen faecal samples of sixteen CF adults) and standardised dietary flavonoid intakes (a validated flavonoid-specific food frequency questionnaire) were analysed using adonis tests. Flavonoid intakes that were significant at a false discovery rate (FDR) $<0.3$ were subjected to Spearman correlation tests with standardised bacterial relative abundances (FDR <0.3). Gallocatechin intakes $(p=0.047, q=0.285)$ were associated with unweighted UniFrac distances. Intakes of apigenin $(p=0.028, q=0.227)$ and kaempferol $(p=0.029, q=0.227)$, and $\%$ flavonoid intake as flavones $(p=0.013$, $q=0.227$ ) and flavonols ( $p=0.016, q=0.227$ ) (both excluding contribution of tea) were associated with weighted UniFrac distances. Among these, gallocatechin correlated with the genus Actinomyces and family Actinomycetaceae (Actinobacteria). Gallocatechin correlated negatively with class Coriobacteriia (Actinobacteria). Intakes of some flavonoids may be associated with GM variations with potential consequences for metabolism, immune function, and inflammation, which are important in CF lung disease and co-morbidity management.
\end{abstract}

Keywords: flavonoids; cystic fibrosis; gut microbiota; inflammation

\section{Introduction}

Survival of people with cystic fibrosis (CF) has improved remarkably with advanced treatment over the past few decades [1]. Concomitantly, a rising trend has been observed in the prevalence and risk of CF-related comorbidities such as CF-related diabetes (CFRD) [2] and gastrointestinal malignancy including colorectal cancer $[1,3]$. Pre-emptive strategies to address these risks therefore need to be incorporated into current therapies. Gut microbiota and their metabolites can influence host metabolism and immune function [4-7], which are heavily implicated in CF progression and comorbidity management [8]. For example, colorectal cancer, as a comorbidity of CF, seems to be associated with a distorted gut microbiota in the general population [9]. In CF, gut microbiota also appears altered [10-12]. Such alteration may even be linked to pulmonary exacerbations and Pseudomonas aeruginosa colonisation [13]. The potential involvement of gut microbiota in CF disease progression and management is thus implicated.

Limited preliminary studies have shown that oral probiotics may help reduce pulmonary exacerbation frequencies and associated hospital admissions [14,15], and gut inflammation and discomfort $[10,16]$ in children and adults with CF [17]. It is thus plausible that modulation of gut 
microbiota in CF may enhance current treatment. However, there seems to be a paucity of such data, potentially due to the lack of more prominent clinical improvement in those probiotic trials when compared with recent CFTR modulator therapies $[18,19]$. Participation in gut microbiota modulation studies may also be considered as unnecessary given the existing high treatment burden [20].

The effect of dietary modulation of gut microbiota has to date focussed on macronutrients and non-digestible carbohydrates [21]. Evidence is emerging that non-nutrient dietary constituents such as flavonoids can also influence gut microbiota composition [22-24]. Population, clinical, and mechanistic studies have also highlighted the association of flavonoid intake with various inflammation-associated chronic conditions such as diabetes and certain cancers including colorectal cancer, at least partially mediated by gut microbial metabolism of various flavonoids $[25,26]$. CF is characterised by inflammation, metabolic abnormality such as CFRD and increased risk of malignancy [1,27]. Flavonoids may thus contribute to the management of CF and comorbidities potentially via modulation by gut microbiota. Investigation on relationships between these dietary flavonoids and gut microbiota in CF has not been reported previously. This study thus explored associations between intakes of dietary flavonoid intakes and gut microbiota composition in a group of free-living adults with CF. The results are considered candidate flavonoids, whose therapeutic potential in CF management requires further examination.

\section{Materials and Methods}

Eighteen free-living adults with stable $\mathrm{CF}$ and signed informed consent were recruited with the help of CF community support organisations in Brisbane and Sydney, Australia. They were clinically stable, which was was defined as having no pulmonary exacerbations, no overnight hospital admission, and no body weight change $>3 \%$ of their body from 8 weeks prior to commencement of the study weight until commencement of the study $[28,29]$. Prior to and during the study, participants were free from cardiac disease, not pregnant, with a bowel frequency between once every two days and three times per day [24]. They were not taking tricyclic antidepressants, narcotics, antacids, anti-diarrhoea medications within four weeks prior to enrolment, and none had been smoking or on total parental nutrition. Those using antibiotics, laxatives, proton pump inhibitors, $\mathrm{H}_{2}$ receptor antagonists, or anticholinergic medications were not excluded, as these are common CF therapeutics [30]. The study was approved by the University Human Research Ethics Committee (Ref No: PBH/39/11/HREC).

Methods of subject recruitment, dietary and clinical information collection, and microbiota analysis have been reported previously [31]. Dietary data other than flavonoids were reported by participants via food diaries on three consecutive days including one weekend day just before faecal sample collection. A validated flavonoid-specific food frequency questionnaire (FFQ) [32] (supplementary notes) was telephone-administered to estimate participants' flavonoid intakes over the year prior to study. A faecal sample from each participant was collected and transported in insulated bags with pre-frozen ice packs and stored at $-20^{\circ} \mathrm{C}$ before transportation to storage at $-80^{\circ} \mathrm{C}$. The storage at $-20^{\circ} \mathrm{C}$ lasted between a couple of days to around ten days. Participants also self-reported demographic and clinical data as summarised in Table S1. The results on flavonoids were analysed and reported separately from other dietary variables because they were collected using different methods.

These faecal samples were then transported on dry ice for DNA extraction and sequencing at the Australian Genome Research Facility (AGRF Ltd, Brisbane, Australia). DNA extracted from approximately $200 \mathrm{mg}$ of each frozen faecal sample was sequenced using primers (Table S2) targeting the V1-V3 hypervariable regions of the bacterial 16 small subunit ribosomal DNA using 454 pyrosequencing. Sequences were analysed and taxonomy assigned using the Quantitative Insights Into Microbial Ecology (QIIME) software package version 1.8 (http:/ / qiime.org/) following default procedures and settings [33]. The sequencing results were, however, demultiplexed and assigned taxonomic identities using open-reference OTU (operational taxonomic unit) picking against the Greengenes OTUs database dated May 2013. Reverse primers and chimeric sequences were removed. 
Taxonomy of the sequencing results with the respective absolute and relative abundances were summarised at the genus, family, order, class, and phylum levels for each sample. Pairwise weighted and unweighted UniFrac distances [34] between samples were calculated after single even-depth rarefaction based on the minimal number of sequences generated among all samples (depth $=2466$ ). Alpha diversity including chao1 and Shannon Index of each sample was also calculated and plotted.

One participant withdrew from the study due to another unspecified commitment and one faecal sample was eliminated during quality control for sequencing, leaving sixteen samples for downstream analyses.

Flavonoid intakes estimated by the flavonoid-specific FFQ [32] are summarised in Table S3. Percentage contributions of flavonoid sub-classes including flavonols, flavones, flavan-3-ols, flavanones, and anthocyanidins to flavonoid intakes excluding tea were also determined.

Estimates of flavonoid intakes were standardised (z-scores) across samples. The overall association between gut microbiota variations (as represented by unweighted and weighted UniFrac distances [34]) among participants and flavonoid intakes were tested using adonis tests [35] adjusted for multiple testing at a false discovery rate $(F D R)<0.3$ [36]. Spearman correlation tests were used to examine the correlations between flavonoids significant at FDR $<0.3$ were subjected to the Spearman correlation test with standardised relative abundances of taxa at the genus, family, order, class, and phylum levels adjusted for multiple testing at an FDR $<0.3$. Statistical analyses were carried out using $R$ (version 3.1.1, R Foundation for Statistical Computing, Vienna, Austria). Adjustment for multiple testing at an FDR $<0.1$ was attempted with nil significant results. A less stringent FDR threshold was applied to not miss any candidate variable [24] in this exploratory study. This approach has been adopted by other studies investigating candidate factors associated with gut microbiota [24,37].

The association between gut microbiota and intakes of macronutrients (including energy, dietary fibre, and resistant starch) and micronutrients followed the same process. The association between gut microbiota and use of medications such as antibiotics, laxatives, and proton pump inhibitors, and other clinical characteristics such as age, gender, BMI, pulmonary function, and use of probiotics was tested using the same approach. The relationship between gut microbiota and micronutrients was previously reported [31]. Other results will be reported separately.

The association between alpha diversity indices at various taxonomic levels and flavonoid intakes was attempted using ANOVA (online software Calypso [38]), with nil significant results and hence not analysed further.

\section{Results}

Details of participants' characteristics are summarised in supplementary Table S1. The predominant phylum in the gut microbiota (Table S4) was Firmicutes ( $86.4 \%$ ), followed by Bacteroidetes (5.6\%), Actinobacteria (5.1\%), unassigned (1.7\%), and Proteobacteria (1.3\%), despite inter-individual differences (Figure S1). Alpha diversity as represented by chao1 and Shannon indices can also be found in Figure S1.

Associations between flavonoid intakes and overall gut microbiota variations among the participants at an FDR $<0.3$ are present in Tables 1 and 2. Among the flavonoids (Table S3) tested, only gallocatechin intake was associated with variations in the presence/absence of bacterial taxa as represented by unweighted UniFrac distances [34]. Intakes of apigenin and kaempferol, and contribution of flavones and flavonols to flavonoid intakes (excluding tea contribution) were associated variations in the presence/absence of bacterial taxa as represented by weighted UniFrac distances [34]. Intakes of flavonoids identified based on weighted UniFrac distances (Table 2) showed stronger associations (larger $R^{2}$ values) with gut microbiota variations than those identified using unweighted UniFrac distances (Table 1).

At an FDR $<0.3$, weighted UniFrac distances were also correlated with gender and use of inhaled antibiotics. These results will be reported and discussed in a separate analysis, together with other 
variables. Due to the limited sample size, it was not feasible to adjust the associations with flavonoids using these other variables.

Among the aforementioned flavonoids that were associated with overall gut microbiota variations, only gallocatechin, a major black tea flavonoid, was found to correlate with specific bacterial taxa that belong to the phylum Actinobacteria (Figure 1 and Figure S2). Gallocatechin intakes correlated positively with Actinomyces and Actinomycetaceae (Actinobacteria), but negatively with the class Coriobacteriia (Actinobacteria). The latter was composed of predominantly Coriobacteriaceae members, correlation of which with gallocatechin intake was similar to Coriobacteriia but became insignificant at an FDR of 0.3 $(r=-0.53, p=0.034, q=0.31)$.

There did not seem to be any correlations between use of oral antibiotic therapy and the relative abundances of Actinomyces ( $r=0.15, p=0.57)$, Actinomycetaceae $(r=0.15, p=0.57)$ or Coriobacteriia $(r=-0.031, p=0.91)$. Thus, the use of oral antibiotics did not seem to influence the associations between gallocatechin and these gut bacterial taxa.

Table 1. Associations between flavonoid intakes ${ }^{1}$ and gut microbiome based on unweighted UniFrac distances.

\begin{tabular}{|c|c|c|c|}
\hline Variable & $p$ Value $^{2}$ & $R^{22}$ & $q$ Value $^{3}$ \\
\hline Gallocatechin & 0.047 & 0.078 & 0.285 \\
\hline Theaflavin digallate & 0.051 & 0.078 & 0.285 \\
\hline Thearubigins & 0.051 & 0.078 & 0.285 \\
\hline Theaflavin & 0.052 & 0.078 & 0.285 \\
\hline Theaflavin-3'-gallate & 0.052 & 0.078 & 0.285 \\
\hline Theaflavin-3-gallate & 0.055 & 0.078 & 0.285 \\
\hline$\%$ Anthocyanidins (excluding tea) & 0.056 & 0.077 & 0.285 \\
\hline Petunidin & 0.087 & 0.076 & 0.387 \\
\hline Peonidin & 0.101 & 0.075 & 0.387 \\
\hline Malvidin & 0.108 & 0.076 & 0.387 \\
\hline Eriodictyol & 0.157 & 0.075 & 0.514 \\
\hline Wine flavonoids & 0.186 & 0.074 & 0.514 \\
\hline Cocoa flavonoids & 0.186 & 0.075 & 0.514 \\
\hline Tea flavonoids & 0.265 & 0.070 & 0.654 \\
\hline Kaempferol & 0.273 & 0.070 & 0.654 \\
\hline Delphinidin & 0.314 & 0.069 & 0.685 \\
\hline Total flavonoids & 0.326 & 0.069 & 0.685 \\
\hline Apigenin & 0.343 & 0.069 & 0.685 \\
\hline Epicatechin & 0.376 & 0.068 & 0.712 \\
\hline \% Flavones (excluding tea) & 0.411 & 0.068 & 0.740 \\
\hline$\%$ Flavan-3-ols (excluding tea) & 0.434 & 0.067 & 0.744 \\
\hline Total flavonoids (excluding tea) & 0.554 & 0.065 & 0.905 \\
\hline Cyanidin & 0.579 & 0.064 & 0.905 \\
\hline Catechin & 0.679 & 0.063 & 0.967 \\
\hline Ouercetin & 0.696 & 0.063 & 0.967 \\
\hline Pelargonidin & 0.702 & 0.062 & 0.967 \\
\hline Naringenin & 0.726 & 0.063 & 0.967 \\
\hline Isorhamnetin & 0.787 & 0.060 & 0.977 \\
\hline Myricetin & 0.791 & 0.061 & 0.977 \\
\hline Luteolin & 0.815 & 0.061 & 0.977 \\
\hline Epicatechin-3-gallate & 0.907 & 0.058 & 0.994 \\
\hline Epigallocatecin & 0.913 & 0.058 & 0.994 \\
\hline Hesperetin & 0.920 & 0.058 & 0.994 \\
\hline \% Flavonols (excluding tea) & 0.944 & 0.058 & 0.994 \\
\hline \% Flavanones (excluding tea) & 0.986 & 0.055 & 0.994 \\
\hline Epigallocatechin-3-gallate & 0.994 & 0.053 & 0.994 \\
\hline
\end{tabular}

${ }^{1}$ Flavonoid-specific food frequency questionnaire validated in the Australian population; ${ }^{2}$ Adonis (R package vegan), bolded $p$ values $<0.05 ;^{3}$ mt.rawp2adjp using "BH" ("fdr") (R package multtest), bolded $q$ values $<0.3$. 
Table 2. Associations between flavonoid intakes ${ }^{1}$ and gut microbiome based on weighted UniFrac distances.

\begin{tabular}{|c|c|c|c|}
\hline Variable & $p$ Value $^{2}$ & $R^{22}$ & $q$ Value $^{3}$ \\
\hline \% Flavones (excluding tea) & 0.013 & 0.184 & 0.227 \\
\hline \% Flavonols (excluding tea) & 0.016 & 0.151 & 0.227 \\
\hline Apigenin & 0.028 & 0.163 & 0.227 \\
\hline Kaempferol & 0.029 & 0.145 & 0.227 \\
\hline Gallocatechin & 0.053 & 0.131 & 0.227 \\
\hline Theaflavin- $3^{\prime}$-gallate & 0.053 & 0.130 & 0.227 \\
\hline Theaflavin-3-gallate & 0.056 & 0.130 & 0.227 \\
\hline Thearubigins & 0.057 & 0.130 & 0.227 \\
\hline Theaflavin digallate & 0.059 & 0.130 & 0.227 \\
\hline Theaflavin & 0.063 & 0.130 & 0.227 \\
\hline Tea flavonoids & 0.087 & 0.113 & 0.285 \\
\hline Total flavonoids & 0.098 & 0.110 & 0.291 \\
\hline Cocoa flavonoids & 0.107 & 0.107 & 0.291 \\
\hline Hesperetin & 0.113 & 0.105 & 0.291 \\
\hline Eriodictyol & 0.127 & 0.103 & 0.305 \\
\hline Pelargonidin & 0.149 & 0.103 & 0.318 \\
\hline Cyanidin & 0.150 & 0.099 & 0.318 \\
\hline Myricetin & 0.165 & 0.096 & 0.324 \\
\hline \% Anthocyanidins (excluding tea) & 0.171 & 0.095 & 0.324 \\
\hline Delphinidin & 0.224 & 0.085 & 0.402 \\
\hline$\%$ Flavanones (excluding tea) & 0.313 & 0.075 & 0.537 \\
\hline Epigallocatecin & 0.341 & 0.071 & 0.542 \\
\hline Epicatechin-3-gallate & 0.346 & 0.072 & 0.542 \\
\hline Catechin & 0.445 & 0.065 & 0.652 \\
\hline \% Flavan-3-ols (excluding tea) & 0.453 & 0.064 & 0.652 \\
\hline Epicatechin & 0.473 & 0.063 & 0.654 \\
\hline Peonidin & 0.495 & 0.060 & 0.659 \\
\hline Petunidin & 0.533 & 0.055 & 0.667 \\
\hline Total flavonoids (excluding tea) & 0.544 & 0.059 & 0.667 \\
\hline Malvidin & 0.559 & 0.053 & 0.667 \\
\hline Ouercetin & 0.574 & 0.054 & 0.667 \\
\hline Wine flavonoids & 0.617 & 0.048 & 0.692 \\
\hline Naringenin & 0.634 & 0.050 & 0.692 \\
\hline Epigallocatechin-3-gallate & 0.704 & 0.044 & 0.745 \\
\hline Isorhamnetin & 0.811 & 0.036 & 0.834 \\
\hline Luteolin & 0.852 & 0.037 & 0.852 \\
\hline
\end{tabular}

${ }^{1}$ Flavonoid-specific food frequency questionnaire validated in the Australian population; ${ }^{2}$ Adonis (R package vegan), bolded $p$ values $<0.05 ;^{3}$ mt.rawp2adjp using "BH" ("fdr") (R package multtest), bolded $q$ values $<0.3$ 
Spearman correlations: Gallocatechin vs. bacterial taxa
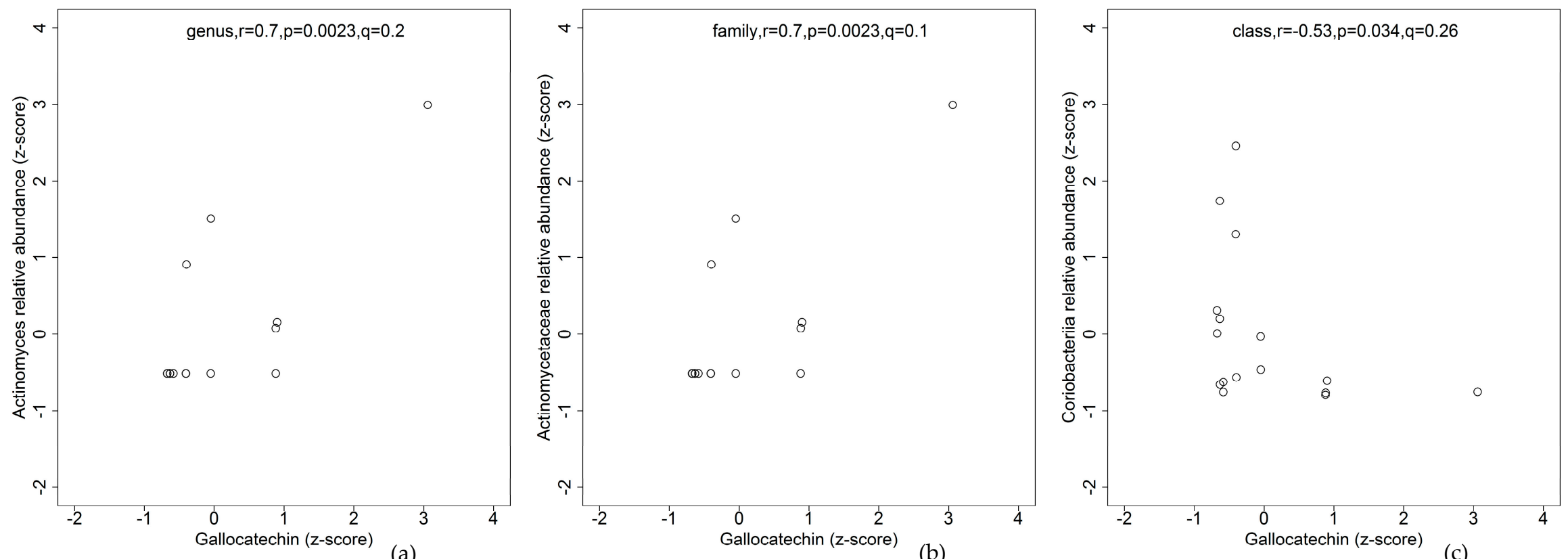

Figure 1. Spearman's correlations between specific gut bacteria taxa and gallocatechin intake in a group of free-living adults with cystic fibrosis (CF). Positive correlations between gallocatechin intake and Actinomyces (a) and Actinomycetaceae (b), negative correlation between gallocatechin intake and Coriobacteriia (c); $r=$ Spearman's rho, $p=$ raw $p$ values, $q=p$ values adjusted for multiple testing at an FDR $<0.3$ 


\section{Discussion}

The present study found associations between intakes of specific flavonoids and gut microbiota in a small group of free-living adults with CF. It should be noted that the current study was part of a broader study on the relationship between various dietary constituents and gut microbiota in CF. Consequently, the results of the study should also be viewed in a broader dietary and clinical context specific to CF.

In this analysis, flavonoids associated with relative abundances (weighted UniFrac distances) of gut bacteria taxa (Table 2) differed from those associated with the presence/absence (unweighted UniFrac distances) of this community (Table 1). Moreover, the associations observed based on weighted UniFrac distances appeared to be stronger than those observed based on unweighted UniFrac distances. This indicates that different flavonoids may associate with variation in either relative abundances or presence/absence of gut bacterial taxa in $\mathrm{CF}$, and the associations with relative abundances may be stronger. The lack of associations between alpha diversity indices and flavonoid intakes implied that the intakes were not associated with community member abundance or evenness in each sample.

The significant associations between intakes of specific flavonoids and gut microbiota variations are notable. Flavonoid intakes data were collected using a flavonoid-specific FFQ [32] intended to assess usual longitudinal intakes. In contrast, participant cross-sectional gut microbiota profiles may fluctuate according to various host and environmental factors including diet [39-41]. Thus, the significant associations between intakes of specific flavonoids and gut microbiota variations observed imply their potential long-term associations and possibly long-term influence of such flavonoids on gut microbiota in CF. Such a relationship is partially supported by the long-term stability [42] and the relatively stable overall inter-individual variations in gut microbiota in response to short-term identical dietary changes [24] in the general population.

In particular, the phylum Actinobacteria seems to be more stable than Firmicutes [42], the predominant phylum in the present study. Since gallocatechin intakes correlated positively with Actinomycetaceae and its lower rank genus Actinomcyes (Actinobacteria), but negatively with Coriobacteriaceae (Actinobacteria) (Figure 1), it is speculated that gallocatechin intakes, of which the predominant dietary source was black tea (Figure S3), may be linked to long-term status of these Actinobacteria members in the gut microbiota in adults with CF. The associations of other black tea flavonoids such as thearubigins and theaflavin and its derivatives with overall gut microbiota variations approached significance (Tables 1 and 2). Furthermore, other tea flavonoid intakes (e.g., epicatechin and derivatives), of which the main dietary sources are not limited to black tea (Figure S3), were not associated with UniFrac distances. These observations suggest that black tea and its major flavonoids may correlate positively with the relative abundance of Actinomcyes and negatively with that of Coriobacteriia, which in this study comprised only taxa from the family Coriobacteriaceae. This is interesting in view of previous in vitro studies using human [43,44] and/or rat faecal bacteria [44]. Specific Coriobacteriaceae strains were found to metabolise epicatechin, catechin [43] and gallocatechin [44]. However, the presence of Actinomcyes spp. was unspecified in one study [43] and the other focused only on four strains of Coriobacteriaceae in the absence of Actinomcyes spp. [44].

The role of gut Actinomyces and Coriobacteriaceae in CF remains undefined, probably because of their lower relative abundances in human gut microbiota studies [45]. However, accumulating evidence suggests a role in macronutrient metabolism, energy homeostasis, infection, and acute immune response in humans [45-48]. Moreover, Actinomyces, together with other anaerobes has been shown to be enriched in a large proportion of CF sputum samples, particularly concurrent with Pseudomonas aeruginosa colonisation and possibly related to different antibiotic regimens [49]. Whether a similar situation occurs in the gut due to antibiotic usage is yet to be confirmed, but the potential link between the gut and respiratory microbiomes in CF [50] indicates a need to evaluate the correlation of Actinomcyes with black tea flavonoids. The role of Coriobacteriaceae in CF remains unclear, but faecal Coriobacteriaceae levels are elevated in those with colorectal cancer compared with healthy controls [51]. Assuming Actinomcyes and Coriobacteriaceae influence the status of CF lung disease and 
colorectal cancer (CRC), and black tea and its flavonoids can indeed modify the gut microbiota in CF, modified nutritional therapies/recommendations incorporating this could have therapeutic potential to complement current management and/or reduce risk of lung disease and CRC in CF. The results presented here stress the need to further investigate the role of black tea consumption in CF nutrition therapy, in view of black tea being a major dietary flavonoid source in a western diet [52].

Despite the absence of significant correlations with specific bacterial taxa, intakes of apigenin and kaempferol were associated with overall gut microbiome variations based on weighted UniFrac distances (Table 2). The same was observed for contribution of flavones (including apigenin and luteolin) and flavonols (including quercetin, isorhamnetin, kaempferol and myricetin) to total flavonoid intakes, excluding contribution of tea flavonoids. Such associations are supported by in vitro studies, in animal [23] and human models [53]. Several mechanisms have been proposed for the influence of polyphenols including flavonoids such as flavones and flavonols on the gut microbiota [54]. These include disrupting bacterial cell-wall/membrane components to impede growth, modulate production of virulence factors, interfering quorum sensing, and supressing bacterial nucleic acid biosynthesis [55]. The potential implications of associations between these flavonoids and gut microbiota in CF management await further investigation. However, flavone intakes may be associated with Blautia that is involved in up-regulation of regulatory T cells [53]. The same study also demonstrated negative associations between flavonol intakes and Bifidibacterium (phylum Actinobacteria). Interestingly, an in vitro study observed that flavonols may increase synthesis of the anti-inflammatory nitric oxide in one Bifidibacterium species upon stimulation by lipopolysaccharide [55]. Lipopolysaccharide, contained in the cell wall of gram-negative bacteria such as $P$. aeruginosa, has been shown to contribute to chronic inflammation in the general population [56], and respiratory inflammation $[57,58]$ and pancreatic exocrine and endocrine dysfunctions mediated by inflammatory pathways involving nuclear factor- $\mathrm{KB}$ [59] in CF. Recurrent inflammation and chronic respiratory colonisation by P. aeruginosa are common in CF [57]. Thus, associations between flavonoid intakes and gut microbiota variations in CF may have implications in management of inflammation-mediated CF co-morbidities.

The generalisability of our observations to the wider CF population is limited by the small sample size, the cross-sectional setting, and the specific methods and conditions in handling and processing faecal samples and sequencing. Inclusion of gut mucosal microbiota samples may also produce different sequencing results [60-65]. All $q$ values were $>0.1$, potentially reflecting the lack of power due to the small sample size. Despite such limitations, this exploratory study was carried out to screen for potential dietary components including candidate flavonoids that may modulate the gut microbiota and influence clinical outcomes of CF. Further studies with a larger sample size and gender-matched healthy controls are warranted to determine whether the flavonoid candidates identified in the present study can modify the gut microbiota in CF.

Although use of FFQ to estimate flavonoid intakes may not be quantitatively accurate, for non-parametric testings of associations and correlations, the ranking of flavonoid intakes rather than absolute intakes was more relevant. Greater than $85 \%$ of participants were placed to the same or adjacent quartile group using the FFQ for total flavonoids, and greater than $73 \%$ for the majority of the individual flavonoids included and all flavonoid subgroups except one, when compared with data collected by seven-day measured food records [32]. Therefore, it was considered appropriate to use this flavonoid-specific FFQ to assess flavonoid intakes for the present study.

The FFQ was used to estimate the habitual intakes of flavonoids. Long-term associations between dietary intakes and clusters of gut microbiota called enterotypes in the general population have been reported [24]. Thus, clustering the gut microbiota profiles in the current study into enterotypes was attempted according to Arumugam et al. [66] and Koren et al. [67]. Stable enterotype clustering was, however, not observed in the present study, probably due to the small sample size, as shown by low Silhouette widths (mostly $<0.3$, recommendation $>0.75$ [67]) and Calinksi-Harabasz scores indicating 
$>10$ number of clusters. The relationship between flavonoid intakes and gut enterotypes in $\mathrm{CF}$ thus needs to be investigated in larger CF cohorts.

These observed associations between certain flavonoids and gut microbiota in the present study warrant further evaluation in larger CF cohorts, preferably in longitudinal settings, on their potential implications in management of $\mathrm{CF}$ lung disease and its ageing- and inflammation-associated co-morbidities such as CFRD and colorectal cancer. Prevalence of these co-morbidities has increased with the much improved survival in CF [1]. Interestingly, the phylum Actinobacteria has been found previously to be more stable than the predominant Firmicutes phylum in humans [42]. Also, the relationship between intakes of other flavonoids (apigenin, kaempferol, \% flavone, and \% flavonol (both excluding tea contribution)), and the gut microbiota in CF needs further investigation, particularly if they also correlate with specific gut bacterial species, considering their aforementioned potential involvement in inflammation and immune regulation. The difficulties in determining causality of dietary components such as flavonoids as modulators of human gut microbiota and hence downstream physiological effects cannot be underestimated [68]. However, faecal transplants from human donors to animal models have demonstrated its usefulness in confirming the role of dietary modulation of gut microbiota in some disease models. Other aspects to be considered in further investigation on effects of dietary modulation of gut microbiota in CF include the influence of other gut microbiota modulating factors such as antibiotics [69] and gender [40] on the effect of dietary modulation of gut microbiota by flavonoids, differences in metabolism between strains of the same gut bacterial species [68], the potential adaptation of phenotypes of particular bacterial species to the CF intestinal environment [70], and variable individual responses (including timeframe and the extent of changes) to dietary modulation of gut microbiota partially due to different individual baseline diets [21]. There seems to be associations between gut microbiota variation and some micronutrients in CF [31]. If both flavonoids and certain micronutrients can modify gut microbiota in $\mathrm{CF}$, it remains to be determined whether the effect is due to individual dietary component or a combination of two or more dietary constituents. The effect size $\left(R^{2}\right)$ of the adonis tests (FDR $\left.<0.3\right)$ (Tables 1 and 2$)$ were similar between the flavonoids and the micronutrients tested [31]. Since micronutrient intake data were recorded in food diaries for the three days prior to the collection of the faecal samples, overall variation in the gut microbiota associated with flavonoid intake recorded in a flavonoid-specific FFQ seemed to be similar to that associated with micronutrient intake recorded in food diaries prior to faecal sample collection.

Diet is among the most modifiable factors that can shape the gut microbiota [24]. Further understanding of the gut microbiota modulatory effect of dietary constituents such as flavonoids may help develop more holistic nutritional therapies targeting multiple CF-related conditions to further improve the quality of life in CF.

Supplementary Materials: The following are available online at http:/ / www.mdpi.com/2072-6643/10/9/1264/ s1. Table S1: Subject clinical characteristics, Table S2: Faecal sample DNA sequencing primers and conditions, Table S3: Flavonoid intakes of subjects over the previous year, Table S4: Taxa composing $\geq 75 \%$ of the gut microbiome at different taxonomic levels; Figure S1: The genus level gut microbiota composition and chao1 and Shannon indices in a group of adults with CF, Figure S2: Heatmap showing correlations between gallocatechin intakes and gut bacterial taxa, Figure S3: Major food sources of tea flavonoids in a group of free-living adults with CF; Supplementary notes: a flavonoid-specific food frequency questionnaire.

Author Contributions: L.L. was engaged in study conceptualisation, data collection and entry, bioinformatics and statistical analyses and manuscript composition. S.S. conceived the study and supervised data collection and entry and bioinformatics and statistical analyses. S.S. also edited the manuscript.

Funding: This research received no external funding.

Acknowledgments: L.L. received the Australian Postgraduate Award from Griffith University, PhD Researcher Grant Scheme from Population and Social Health Research Program, Griffith University, PhD completion assistance scholarship from Griffith University, and PhD Student Fellowship from The Australian Cystic Fibrosis Research Trust (ACFRT). None of the funding sources were involved in the conception of the study or the preparation of the manuscript. The authors would like to thank Miraa Best and Jane Andersen from Cystic Fibrosis (CF) New South Wales and CF Queensland, respectively, for their contribution during participant recruitment. All participants are thanked for their time and contribution. Jutta Zwielehner, a former postdoctoral 
research fellow at the University of Queensland is thanked for helping conceive the study. Thanks are also owed to Martha Zakrzewski at Queensland Institute of Medical Research for her advice and help with bioinformatics and statistical analyses.

Conflicts of Interest: The authors declare no conflict of interest. The founding sponsors had no role in the design of the study; in the collection, analyses, or interpretation of data; in the writing of the manuscript, and in the decision to publish the results.

\section{References}

1. Parkins, M.D.; Parkins, V.M.; Rendall, J.C.; Elborn, S. Changing epidemiology and clinical issues arising in an ageing cystic fibrosis population. Ther. Adv. Respir. Dis. 2011, 5, 105-119. [CrossRef] [PubMed]

2. Moran, A.; Becker, D.; Casella, S.J.; Gottlieb, P.A.; Kirkman, M.S.; Marshall, B.C.; Slovis, B.; CFRD Consensus Conference Committee. Epidemiology, pathophysiology, and prognostic implications of cystic fibrosis-related diabetes. Diabetes Care 2010, 33, 2677-2683. [CrossRef] [PubMed]

3. Gory, I.; Brown, G.; Wilson, J.; Kemp, W.; Paul, E.; Roberts, S.K. Increased risk of colorectal neoplasia in adult patients with cystic fibrosis: A matched case-control study. Scand. J. Gastroenterol. 2014, 49, 1230-1236. [CrossRef] [PubMed]

4. Atarashi, K.; Tanoue, T.; Oshima, K.; Suda, W.; Nagano, Y.; Nishikawa, H.; Fukuda, S.; Saito, T.; Narushima, S.; Hase, K.; et al. Treg induction by a rationally selected mixture of clostridia strains from the human microbiota. Nature 2013, 500, 232-236. [CrossRef] [PubMed]

5. Rosser, E.C.; Oleinika, K.; Tonon, S.; Doyle, R.; Bosma, A.; Carter, N.A.; Harris, K.A.; Jones, S.A.; Klein, N.; Mauri, C. Regulatory b cells are induced by gut microbiota-driven interleukin-1[beta] and interleukin-6 production. Nat. Med. 2014, 20, 1334-1339. [CrossRef] [PubMed]

6. Tolhurst, G.; Heffron, H.; Lam, Y.S.; Parker, H.E.; Habib, A.M.; Diakogiannaki, E.; Cameron, J.; Grosse, J.; Reimann, F.; Gribble, F.M. Short-chain fatty acids stimulate glucagon-like peptide-1 secretion via the g-protein-coupled receptor ffar2. Diabetes 2012, 61, 364-371. [CrossRef] [PubMed]

7. Vinolo, M.A.R.; Rodrigues, H.G.; Nachbar, R.T.; Curi, R. Regulation of inflammation by short chain fatty acids. Nutrients 2011, 3, 858-876. [CrossRef] [PubMed]

8. Smyth, A.R.; Bell, S.C.; Bojcin, S.; Bryon, M.; Duff, A.; Flume, P.; Kashirskaya, N.; Munck, A.; Ratjen, F.; Schwarzenberg, S.J.; et al. European cystic fibrosis society standards of care: Best practice guidelines. J. Cyst. Fibros. 2014, 13, S23-S42. [CrossRef] [PubMed]

9. Louis, P.; Hold, G.L.; Flint, H.J. The gut microbiota, bacterial metabolites and colorectal cancer. Nat. Rev. Microbiol. 2014, 12, 661-672. [CrossRef] [PubMed]

10. Bruzzese, E.; Callegari, M.L.; Raia, V.; Viscovo, S.; Scotto, R.; Ferrari, S.; Morelli, L.; Buccigrossi, V.; Lo Vecchio, A.; Ruberto, E.; et al. Disrupted intestinal microbiota and intestinal inflammation in children with cystic fibrosis and its restoration with lactobacillus GG: A randomised clinical trial. PLoS ONE 2014, 9, e87796. [CrossRef] [PubMed]

11. Duytschaever, G.; Huys, G.; Bekaert, M.; Boulanger, L.; De Boeck, K.; Vandamme, P. Dysbiosis of bifidobacteria and clostridium cluster xiva in the cystic fibrosis fecal microbiota. J. Cyst. Fibros. 2013, 12, 206-215. [CrossRef] [PubMed]

12. Scanlan, P.D.; Buckling, A.; Kong, W.; Wild, Y.; Lynch, S.V.; Harrison, F. Gut dysbiosis in cystic fibrosis. J. Cyst. Fibros. 2012, 11, 454-455. [CrossRef] [PubMed]

13. Hoen, A.G.; Li, J.; Moulton, L.A.; O’Toole, G.A.; Housman, M.L.; Koestler, D.C.; Guill, M.F.; Moore, J.H.; Hibberd, P.L.; Morrison, H.G.; et al. Associations between gut microbial colonization in early life and respiratory outcomes in cystic fibrosis. J. Pediatr. 2015, 167, 138-147. [CrossRef] [PubMed]

14. Jafari, S.-A.; Mehdizadeh-Hakkak, A.; Kianifar, H.-R.; Hebrani, P.; Ahanchian, H.; Abbasnejad, E. Effects of probiotics on quality of life in children with cystic fibrosis; a randomized controlled trial. Iran. J. Pediatr. 2013, 23, 669-674. [PubMed]

15. Weiss, B.; Bujanover, Y.; Yahav, Y.; Vilozni, D.; Fireman, E.; Efrati, O. Probiotic supplementation affects pulmonary exacerbations in patients with cystic fibrosis: A pilot study. Pediatr. Pulmonol. 2010, 45, 536-540. [CrossRef] [PubMed] 
16. Del Campo, R.; Garriga, M.; Pérez-Aragón, A.; Guallarte, P.; Lamas, A.; Máiz, L.; Bayón, C.; Roy, G.; Cantón, R.; Zamora, J.; et al. Improvement of digestive health and reduction in proteobacterial populations in the gut microbiota of cystic fibrosis patients using a lactobacillus reuteri probiotic preparation: A double blind prospective study. J. Cyst. Fibros. 2014, 13, 716-722. [CrossRef] [PubMed]

17. Van Biervliet, S.; Declercq, D.; Somerset, S. Clinical effects of probiotics in cystic fibrosis patients: A systematic review. Clin. Nutr. ESPEN 2017, 18, 37-43. [CrossRef] [PubMed]

18. Patel, S.; Sinha, I.P.; Dwan, K.; Carlos, E.; Schechter, M.; Southern, K.W. Potentiators (specific therapies for class iii and iv mutations) for cystic fibrosis. Cochrane Database Syst. Rev. 2015. [CrossRef] [PubMed]

19. Wainwright, C.E.; Elborn, J.S.; Ramsey, B.W.; Marigowda, G.; Huang, X.; Cipolli, M.; Colombo, C.; Davies, J.C.; De Boeck, K.; Flume, P.A.; et al. Lumacaftor-ivacaftor in patients with cystic fibrosis homozygous for phe508del cftr. N. Engl. J. Med. 2015, 373, 220-231. [CrossRef] [PubMed]

20. Sawicki, G.S.; Sellers, D.E.; Robinson, W.M. High treatment burden in adults with cystic fibrosis: Challenges to disease self-management. J. Cyst. Fibros. 2009, 8, 91-96. [CrossRef] [PubMed]

21. Healey, G.R.; Murphy, R.; Brough, L.; Butts, C.A.; Coad, J. Interindividual variability in gut microbiota and host response to dietary interventions. Nutr. Rev. 2017, 75, 1059-1080. [CrossRef] [PubMed]

22. Duda-Chodak, A. The inhibitory effect of polyphenols on human gut microbiota. J. Physiol. Pharmacol. 2012, 63, 497-503. [PubMed]

23. Etxeberria, U.; Fernández-Quintela, A.; Milagro, F.I.; Aguirre, L.; Martínez, J.A.; Portillo, M.P. Impact of polyphenols and polyphenol-rich dietary sources on gut microbiota composition. J. Agric. Food Chem. 2013, 61, 9517-9533. [CrossRef] [PubMed]

24. Wu, G.D.; Chen, J.; Hoffmann, C.; Bittinger, K.; Chen, Y.-Y.; Keilbaugh, S.A.; Bewtra, M.; Knights, D.; Walters, W.A.; Knight, R.; et al. Linking long-term dietary patterns with gut microbial enterotypes. Science 2011, 334, 105-108. [CrossRef] [PubMed]

25. Cassidy, A.; Minihane, A.-M. The role of metabolism (and the microbiome) in defining the clinical efficacy of dietary flavonoids. Am. J. Clin. Nutr. 2017, 105, 10-22. [CrossRef] [PubMed]

26. Lu, M.-F.; Xiao, Z.-T.; Zhang, H.-Y. Where do health benefits of flavonoids come from? Insights from flavonoid targets and their evolutionary history. Biochem. Biophys. Res. Commun. 2013, 434, 701-704. [CrossRef] [PubMed]

27. Reverri, E.J.; Morrissey, B.M.; Cross, C.E.; Steinberg, F.M. Inflammation, oxidative stress, and cardiovascular disease risk factors in adults with cystic fibrosis. Free Radic. Biol. Med. 2014, 76, 261-277. [CrossRef] [PubMed]

28. Richardson, I.; Nyulasi, I.; Cameron, K.; Ball, M.; Wilson, J. Nutritional status of an adult cystic fibrosis population. Nutrition 2000, 16, 255-259. [CrossRef]

29. Olveira, G.; Dorado, A.; Olveira, C.; Padilla, A.; Rojo-Martínez, G.; García-Escobar, E.; Gaspar, I.; Gonzalo, M.; Soriguer, F. Serum phospholipid fatty acid profile and dietary intake in an adult mediterranean population with cystic fibrosis. Br. J. Nutr. 2006, 96, 343-349. [CrossRef] [PubMed]

30. CFA. Cystic Fibrosis in Australia 2011: 14th Annual Report from the Australian Cystic Fibrosis Data Registry; Cystic Fibrosis Australia: Sydney, Australia, 2012; p. 42. ISSN 1447-3933.

31. Li, L.; Krause, L.; Somerset, S. Associations between micronutrient intakes and gut microbiota in a group of adults with cystic fibrosis. Clin. Nutr. 2017, 36, 1097-1104. [CrossRef] [PubMed]

32. Somerset, S.; Papier, K. A food frequency questionnaire validated for estimating dietary flavonoid intake in an australian population. Nutr. Cancer 2014, 66, 1200-1210. [CrossRef] [PubMed]

33. Caporaso, J.G.; Kuczynski, J.; Stombaugh, J.; Bittinger, K.; Bushman, F.D.; Costello, E.K.; Fierer, N.; Peña, A.G.; Goodrich, J.K.; Gordon, J.I.; et al. Qiime allows analysis of high-throughput community sequencing data. Nat. Methods 2010, 7, 335-336. [CrossRef] [PubMed]

34. Lozupone, C.A.; Hamady, M.; Kelley, S.T.; Knight, R. Quantitative and qualitative $\beta$ diversity measures lead to different insights into factors that structure microbial communities. Appl. Environ. Microbiol. 2007, 73, 1576-1585. [CrossRef] [PubMed]

35. Oksanen, J.; Blanchet, F.G.; Kindt, R.; Legendre, P.; Minchin, P.R.; O’Hara, R.B.; Simpson, G.L.; Solymos, P.; Stevens, M.H.H.; Wagner, H. Vegan: Community Ecology Package. R Package Version 2.0-10. 2013. Available online: http:/ / cran.rproject.org/package=vegan (accessed on 9 December 2014). 
36. Pollard, K.S.; Dudoit, S.; van der Laan, M.J. Multiple testing procedures: R multtest package and applications to genomics. In Bioinformatics and Computational Biology Solutions Using $r$ and Bioconductor; Gentleman, R., Carey, V., Huber, W., Irizarry, R., Dudoit, S., Eds.; Springer: Berlin, Germany, 2005; pp. 251-272.

37. Lu, W.; Feng, Y.; Jing, F.; Han, Y.; Lyu, N.; Liu, F.; Li, J.; Song, X.; Xie, J.; Qiu, Z.; et al. Association between gut microbiota and cd4 recovery in HIV-1 infected patients. Front. Microbiol. 2018, 9. [CrossRef] [PubMed]

38. Zakrzewski, M.; Proietti, C.; Ellis, J.J.; Hasan, S.; Brion, M.-J.; Berger, B.; Krause, L. Calypso: A user-friendly web-server for mining and visualizing microbiome-environment interactions. Bioinformatics 2017, 33, 782-783. [CrossRef] [PubMed]

39. Maukonen, J.; Saarela, M. Human gut microbiota: Does diet matter? Proc. Nutr. Soc. 2015, 74, 23-36. [CrossRef] [PubMed]

40. Spor, A.; Koren, O.; Ley, R. Unravelling the effects of the environment and host genotype on the gut microbiome. Nat. Rev. Microbiol. 2011, 9, 279-290. [CrossRef] [PubMed]

41. Yatsunenko, T.; Rey, F.E.; Manary, M.J.; Trehan, I.; Dominguez-Bello, M.G.; Contreras, M.; Magris, M.; Hidalgo, G.; Baldassano, R.N.; Anokhin, A.P.; et al. Human gut microbiome viewed across age and geography. Nature 2012, 486, 222-227. [CrossRef] [PubMed]

42. Faith, J.J.; Guruge, J.L.; Charbonneau, M.; Subramanian, S.; Seedorf, H.; Goodman, A.L.; Clemente, J.C.; Knight, R.; Heath, A.C.; Leibel, R.L.; et al. The long-term stability of the human gut microbiota. Science 2013, 341. [CrossRef] [PubMed]

43. Kutschera, M. Isolation of catechin-converting human intestinal bacteria catechin-converting bacteria. J. Appl. Microbiol. 2011, 111, 165-175. [CrossRef] [PubMed]

44. Takagaki, A.; Nanjo, F. Biotransformation of (-)-epigallocatechin and (-)-gallocatechin by intestinal bacteria involved in isoflavone metabolism. Biol. Pharm. Bull. 2015, 38, 325-330. [CrossRef] [PubMed]

45. Hoyles, L.; Clear, J.A.; McCartney, A.L. Use of denaturing gradient gel electrophoresis to detect actinobacteria associated with the human faecal microbiota. Anaerobe 2013, 22, 90-96. [CrossRef] [PubMed]

46. Claus, S.P.; Ellero, S.L.; Berger, B.; Krause, L.; Bruttin, A.; Molina, J.; Paris, A.; Want, E.J.; de Waziers, I.; Cloarec, O.; et al. Colonization-induced host-gut microbial metabolic interaction. mBio 2011, 2. [CrossRef] [PubMed]

47. Martinez, I.; Lattimer, J.M.; Hubach, K.L.; Case, J.A.; Yang, J.; Weber, C.G.; Louk, J.A.; Rose, D.J.; Kyureghian, G.; Peterson, D.A.; et al. Gut microbiome composition is linked to whole grain-induced immunological improvements. ISME J. 2013, 7, 269-280. [CrossRef] [PubMed]

48. Walker, A.W.; Ince, J.; Duncan, S.H.; Webster, L.M.; Holtrop, G.; Ze, X.; Brown, D.; Stares, M.D.; Scott, P.; Bergerat, A.; et al. Dominant and diet-responsive groups of bacteria within the human colonic microbiota. ISME J. 2011, 5, 220-230. [CrossRef] [PubMed]

49. Tunney, M.M.; Field, T.R.; Moriarty, T.F.; Patrick, S.; Doering, G.; Muhlebach, M.S.; Wolfgang, M.C.; Boucher, R.; Gilpin, D.F.; McDowell, A.; et al. Detection of anaerobic bacteria in high numbers in sputum from patients with cystic fibrosis. Am. J. Respir. Crit. Care Med. 2008, 177, 995-1001. [CrossRef] [PubMed]

50. Madan, J.C.; Koestler, D.C.; Stanton, B.A.; Davidson, L.; Moulton, L.A.; Housman, M.L.; Moore, J.H.; Guill, M.F.; Morrison, H.G.; Sogin, M.L.; et al. Serial analysis of the gut and respiratory microbiome in cystic fibrosis in infancy: Interaction between intestinal and respiratory tracts and impact of nutritional exposures. mBio 2012, 3, e00251-12. [CrossRef] [PubMed]

51. Chen, W.; Liu, F.; Ling, Z.; Tong, X.; Xiang, C. Human intestinal lumen and mucosa-associated microbiota in patients with colorectal cancer. PLoS ONE 2012, 7, e39743. [CrossRef] [PubMed]

52. Somerset, S.M.; Johannot, L. Dietary flavonoid sources in australian adults. Nutr. Cancer 2008, 60, 442-449. [CrossRef] [PubMed]

53. Cuervo, A.; Hevia, A.; López, P.; Suárez, A.; Sánchez, B.; Margolles, A.; González, S. Association of polyphenols from oranges and apples with specific intestinal microorganisms in systemic lupus erythematosus patients. Nutrients 2015, 7, 1301-1317. [CrossRef] [PubMed]

54. Cardona, F.; Andrés-Lacueva, C.; Tulipani, S.; Tinahones, F.J.; Queipo-Ortuño, M.I. Benefits of polyphenols on gut microbiota and implications in human health. J. Nutr. Biochem. 2013, 24, 1415-1422. [CrossRef] [PubMed]

55. Kawabata, K.; Sugiyama, Y.; Sakano, T.; Ohigashi, H. Flavonols enhanced production of anti-inflammatory substance(s) by bifidobacterium adolescentis: Prebiotic actions of galangin, quercetin, and fisetin. Biofactors 2013, 39, 422-429. [CrossRef] [PubMed] 
56. Cani, P.D.; Everard, A.; Duparc, T. Gut microbiota, enteroendocrine functions and metabolism. Curr. Opin. Pharm. 2013, 13, 935-940. [CrossRef] [PubMed]

57. Cohen, T.S.; Prince, A. Cystic fibrosis: A mucosal immunodeficiency syndrome. Nat. Med. 2012, 18, 509-519. [CrossRef] [PubMed]

58. Porro, C.; Di Gioia, S.; Trotta, T.; Lepore, S.; Panaro, M.A.; Battaglino, A.; Ratclif, L.; Castellani, S.; Bufo, P.; Martinez, M.C.; et al. Pro-inflammatory effect of cystic fibrosis sputum microparticles in the murine lung. J. Cyst. Fibros. 2013, 12, 721-728. [CrossRef] [PubMed]

59. Constantinescu, A.A.; Gleizes, C.; Alhosin, M.; Yala, E.; Zobairi, F.; Leclercq, A.; Stoian, G.; Mitrea, I.L.; Prévost, G.; Toti, F.; et al. Exocrine cell-derived microparticles in response to lipopolysaccharide promote endocrine dysfunction in cystic fibrosis. J. Cyst. Fibros. 2014, 13, 219-226. [CrossRef] [PubMed]

60. Eckburg, P.B.; Bik, E.M.; Bernstein, C.N.; Purdom, E.; Dethlefsen, L.; Sargent, M.; Gill, S.R.; Nelson, K.E.; Relman, D.A. Diversity of the human intestinal microbial flora. Science 2005, 308, 1635-1638. [CrossRef] [PubMed]

61. Macfarlane, S.; Dillon, J.F. Microbial biofilms in the human gastrointestinal tract. J. Appl. Microbiol. 2007, 102, 1187-1196. [CrossRef] [PubMed]

62. Marteau, P.; Pochart, P.; Doré, J.; Béra-Maillet, C.; Bernalier, A.; Corthier, G. Comparative study of bacterial groups within the human cecal and fecal microbiota. Appl. Environ. Microbiol. 2001, 67, 4939-4942. [CrossRef] [PubMed]

63. Momozawa, Y.; Deffontaine, V.; Louis, E.; Medrano, J.F. Characterization of bacteria in biopsies of colon and stools by high throughput sequencing of the v2 region of bacterial 16s rrna gene in human. PLOS ONE 2011, 6, e16952. [CrossRef] [PubMed]

64. Zoetendal, E.G.; von Wright, A.; Vilpponen-Salmela, T.; Ben-Amor, K.; Akkermans, A.D.L.; de Vos, W.M. Mucosa-associated bacteria in the human gastrointestinal tract are uniformly distributed along the colon and differ from the community recovered from feces. Appl. Environ. Microbiol. 2002, 68, 3401-3407. [CrossRef] [PubMed]

65. Guarner, F.; Malagelada, J.-R. Gut flora in health and disease. Lancet 2003, 361, 512-519. [CrossRef]

66. Arumugam, M.; Raes, J.; Pelletier, E.; Le Paslier, D.; Yamada, T.; Mende, D.R.; Fernandes, G.R.; Tap, J.; Bruls, T.; Batto, J.-M.; et al. Enterotypes of the human gut microbiome. Nature 2011, 473, 174-180. [CrossRef] [PubMed]

67. Koren, O.; Knights, D.; Gonzalez, A.; Waldron, L.; Segata, N.; Knight, R.; Huttenhower, C.; Ley, R.E. A guide to enterotypes across the human body: Meta-analysis of microbial community structures in human microbiome datasets. PLoS Comput. Biol. 2013, 9, e1002863. [CrossRef] [PubMed]

68. Lam, Y.Y.; Zhang, C.; Zhao, L. Causality in dietary interventions-Building a case for gut microbiota. Genome Med. 2018, 10. [CrossRef] [PubMed]

69. Ferrer, M.; Martins dos Santos, V.A.P.; Ott, S.J.; Moya, A. Gut microbiota disturbance during antibiotic therapy. Gut Microbes 2013, 5, 64-70. [CrossRef] [PubMed]

70. Matamouros, S.; Hayden, H.S.; Hager, K.R.; Brittnacher, M.J.; Lachance, K.; Weiss, E.J.; Pope, C.E.; Imhaus, A.-F.; McNally, C.P.; Borenstein, E.; et al. Adaptation of commensal proliferating escherichia coli to the intestinal tract of young children with cystic fibrosis. Proc. Natl. Acad. Sci. USA 2018, 115, 1605-1610. [CrossRef] [PubMed]

(c) 2018 by the authors. Licensee MDPI, Basel, Switzerland. This article is an open access article distributed under the terms and conditions of the Creative Commons Attribution (CC BY) license (http:// creativecommons.org/licenses/by/4.0/). 